\title{
Some Matters relating to Urban Management aiming to Reduction of Environmental Pollution
}

\author{
Cong Tri Tran, Van Huong Dong
}

\begin{abstract}
Urban areas are constantly developing and rapidly, especially in recent times. According to the United Nations, in 1950 the global urban population accounted for only $29 \%$ of the world's population; this figure was $50 \%$ in 2009 and will be $60 \%$ in 2030 with about 5 billion people. In Vietnam, urban population is projected to account for $38 \%$ of the country's population by $2015,45 \%$ of the country's population in 2020 and $50 \%$ of the national population by 2025 with about 25 million. In the process of urbanization with growth and development, cities often face significant challenges. These are: 1) Unbalanced development, over-focus on large cities makes the development gap between urban and rural areas more and more increasing; 2) Unsustainable development, rapid technical and social infrastructure systems degrading rapidly, especially housing and environmental sanitation; 3) The administrative management capacity of urban governments must often chase the rapid growth of urban areas; 4) Poverty, crime and unemployment often occur in rapidly growing cities but lack solid economic and technical bases. In order to have an identity of sustainable urban development, development cannot be separated from preserving stability in which urban management is always a very important task.
\end{abstract}

Index Terms-Climate Change, Environmental Management, Urban Environment.

\section{INTRODUCTION}

Urban management is a comprehensive science, built on the basis of many specialized sciences, including the system of policies, mechanisms, measures and means used by governments at all levels to create facilitating and controlling the process of urban growth and development in order to effectively implement the expected objectives. Urban management is primarily the exercise of public power, in the name of the State. Therefore, urban management is above all state management in urban areas, urban management demonstrates the nature and role of the State for a residential area. However, modern urban management has the participation of social, professional, non-governmental and community organizations. Urban management from another perspective is also the mobilization of human and financial resources through governmental, non-governmental and community organizations to achieve the goals of society in the capital. Urban management is a process of developing, researching and evaluating strategies integrated with the help of other relevant urban actors, taking into account the goals of the private sector and the relationship. The focus of the public

Published on September 19, 2019

Authors are with Ho Chi Minh city University of Transport, Ho Chi Minh city, Vietnam. sector within the framework of the State's policies to determine the creation and exploitation of resources for solid economic development. The general role of urban management is to improve the competitive position of one region by reducing the gaps between supply and demand of similar local actors from one region to another. Urban management has become a very important topic for governments and international development organizations around the world. Management has been broadly defined as making jobs completed through personnel. Management involves making decisions or selecting ways of organizing, protecting and using resources to produce goods and services for consumption, trade, enjoyment or to build capital and assets for future development. Current urban management is strongly developing based on the use of modern tools and techniques. The new concern of urban managers is the provision of perfect technical services for urban life. As a result, urban management became highly specialized, with the formation of urban services such as traffic control, underground engineering, waste treatment, etc. Urban management when specialized will represent the population, administrative apparatus and law enforcement. The internal organization of the executive is also built separately from the functional parts such as the application of laws: licensing, control of compliance with laws and technical services such as construction and maintenance of the lower system. technical floor and provide urban comfort service Vietnam is suffering from climate change (climate change), natural disasters, floods, storms and droughts. This is obvious and undeniable. Under these circumstances, sectors, branches and localities should carry out research activities, evaluate the situation, developments and impacts of climate change on natural resources, the environment and socio-economic development (Socio-economic), propose and initially implement coping solutions, and in the long term integrate climate change response goals into their regular activities[1]. Vietnam has developed a National Target Program to For cities, effective urban environment management aims to reduce the impacts of climate change[2]. The purpose of this report is to study climate change-oriented policy solutions related to urban environmental management in Ho Chi Minh City[3]. In particular, three key issues will be focused on: Air quality management, water management (water supply and drainage) and solid waste management. Respond to climate change2 (Decision 158/2008 / QD-TTg dated 2 December 2008). On October 13, 2009, the Ministry of Natural Resources and Environment (MONRE) also announced the Framework for developing action plans to respond to climate change of ministries, sectors and localities. Ho Chi Minh City (HCMC) is a vibrant city. Rapid economic 
growth, population growth and the presence of many sociocultural organizations are characteristics of the city that have been expanding rapidly over the past decades [4]. Most industries and ports in southern Vietnam are concentrated in Ho Chi Minh City or neighboring provinces. The city is like an international trading center with seaports located at the intersection of strategic international maritime routes[5]. urban management and planning management still have many limitations such as many planning but lack of linkage because there is no national and regional planning; planning of infrastructure industries is still fragmented and lacks synchronism; planning of economic sectors, goods and service manufacturing industries are not suitable because of low quality, rigidity and less feasibility; the planning is regularly adjusted to meet the requirements of socio- economic development; a number of construction planning projects are of low quality, not highly feasible, not yet longterm strategic, and not yet leading. Planning officials are still limited in awareness, expertise and capacity.

In addition, the infrastructure system is focused on investment and gradually improved but lacks synchronism among fields, fails to develop promptly and fails to meet the requirements of economic growth, increasing population size. With a large city, the infrastructure has not promoted its particular strength and has not really been a breakthrough. The demand for investment capital for infrastructure development compared with the ability to balance the city budget is becoming a hot issue. Every year, the budget capital for infrastructure development only meets about $22 \%$ of the total capital demand.

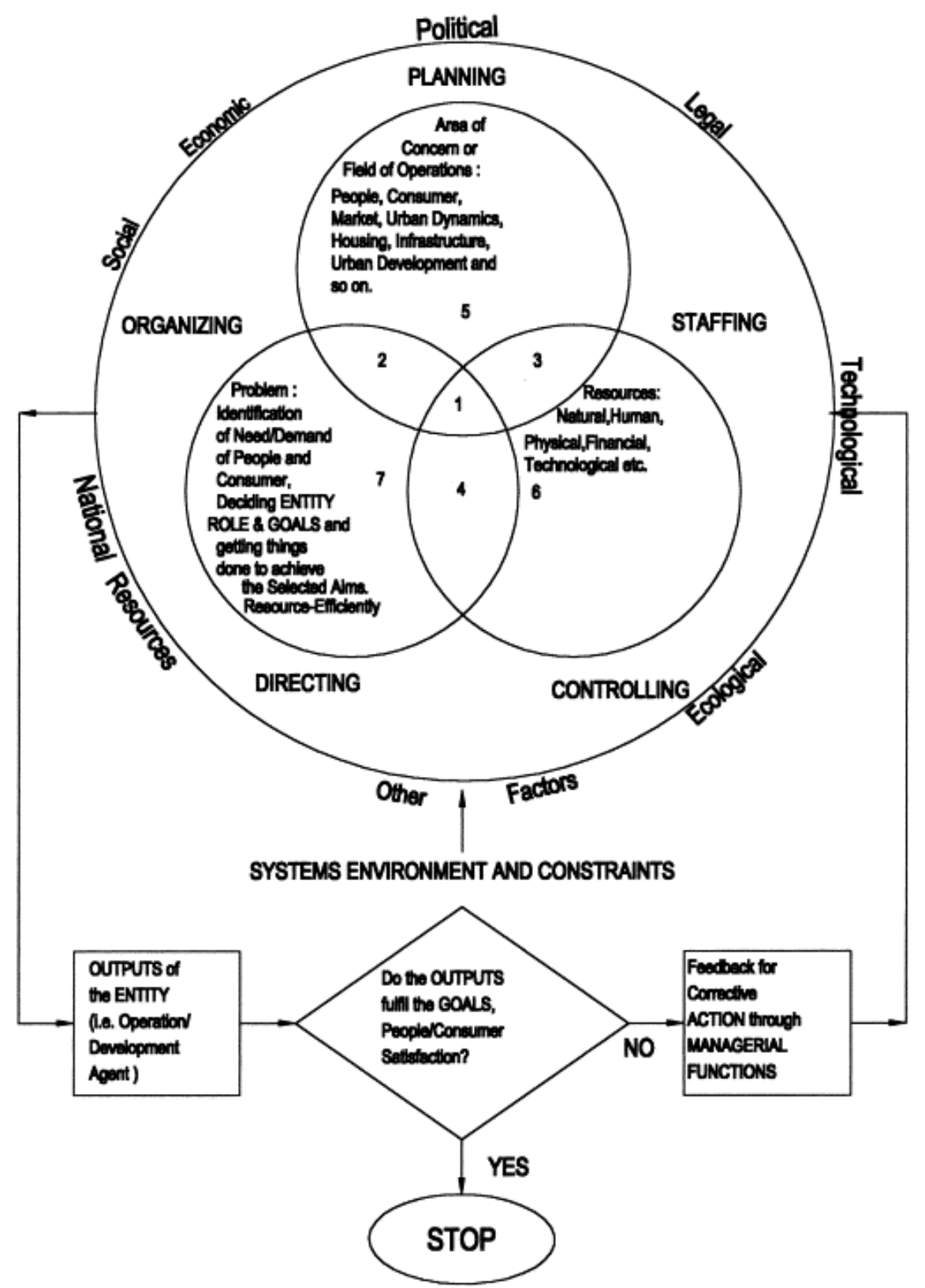

Fig. 1. Urban management plan

\section{Climate Change Problem}

With a natural area of 2,095 km2 and a population of over 10 million people, Ho Chi Minh City is a special urban area with an important position and role for the socio-economic development of Vietnam. For many years, Ho Chi Minh City has always been one of the leading localities in terms of GDP growth rate, contributing about $23 \%$ of gross domestic product, $30 \%$ of total budget revenue, more than $1 / 4$ of total revenue annually. export turnover and attract $44 \%$ of total 
foreign investment projects into Vietnam. Labor productivity of Ho Chi Minh City is 3 times higher than the average labor productivity of the whole country. On $1 \mathrm{~km} 2$ in Ho Chi Minh City, there are 4,773 people, 17 times the national average. On $1 \mathrm{~km} 2$ of Ho Chi Minh City, domestic products are created 36 times, the tax revenue is 45 times the national average. However, domestic waste, domestic water demand and traffic density per $1 \mathrm{~km} 2$ in Ho Chi Minh City are 17 times larger than the country, which is a huge challenge for ensuring a good living environment for the people and for the city. Ho Chi Minh City is more sensitive to the impact of climate change. In terms of natural conditions, Ho Chi Minh City is located at the gateway of the Saigon - Dong Nai River, with low terrain, so recently, it has faced a new challenge of the era, which is the effects of climate change. Organization for Economic Co-operation and Development (OECD) considers Ho Chi Minh City as one of the 10 cities in the world most threatened by climate change. According to the scenario issued by the Ministry of Natural Resources and Environment in 2016, if the sea level rises $100 \mathrm{~cm}, 17.84 \%$ of Ho Chi Minh City area will be inundated, of which, Binh Thanh District will be $80.78 \%$ and Binh Chanh District will be flooded with $36.43 \%$ acreage. Ho Chi Minh City is expanding quickly and the urban density is increasing. The increase in pressure on space has a downside: the plots of land reserved for urban green spaces decrease and the adjacent construction areas can encroach on the natural water system[6]. As natural vegetation and water systems are being compromised through urban development, the result is more frequent flooding due to high rainfall and river flows[7]. In addition to these rapid economic-driven developments, two slower and more difficult-to-recognize processes are becoming increasingly important to the city's future. The first is climate change that leads to rising sea levels, changing rain patterns and increasing average temperatures. Secondly, subsidence occurs in many parts of the city, making these areas vulnerable to flooding. Especially since the mid1990 s, the intensity, frequency and duration of floods is increasing[8]. According to the 2007 - 2008 Human Development Report of UNDP 1, with the rising sea level scenario, by 2100 , the average temperature increase of 3-4 degrees $\mathrm{C}$ will have about 22 million Vietnamese people affected. In particular, the Mekong Delta region will be completely flooded, causing agricultural productivity to decrease by $20 \%$ [9]. Floods, floods also increased. Diseases, especially dengue fever and malaria, have flourished, affecting people's health. With the development of road transport, the development of inland waterway transport is now a key task of the transport sector. Recently, Vietnamese Inland Waterway Administration has completed the detailed outline of the inland waterway system in the North to 2020 with orientation to 2030. In the future, the system of waterway ports will become the center connects to other modes of transport[10], contributing significantly to socioeconomic development in the localities.

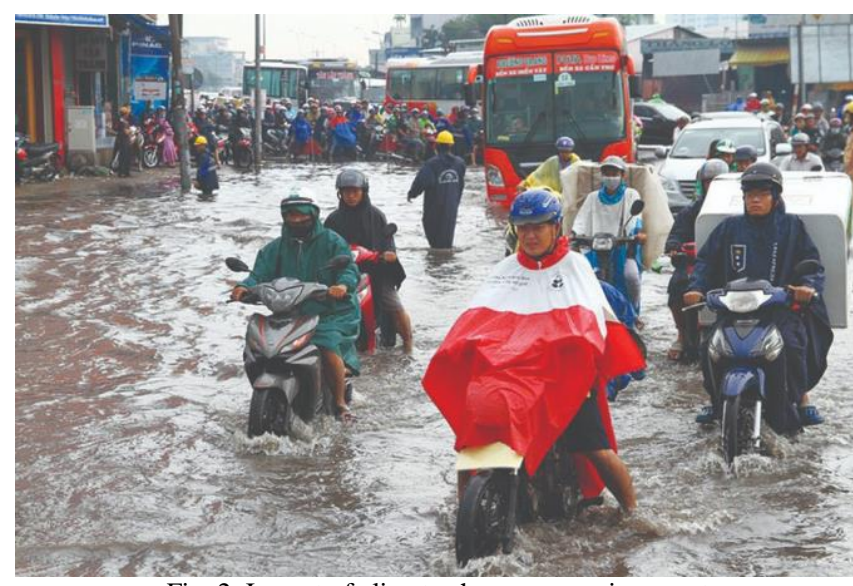

Fig. 2. Impact of climate change on environment

For cities, effective urban environment management aims to reduce the impacts of climate change. The purpose of this report is to study climate change-oriented policy solutions related to urban environmental management in Ho Chi Minh City [11]. In particular, three key issues will be focused on: Air quality management, water management (water supply and drainage) and solid waste management [3]. Meanwhile, based on measurement data of the Southern Hydrometeorology Station shows that Ho Chi Minh City is getting warmer and hotter. The number of days with temperatures above $35^{\circ} \mathrm{C}$ is increasing sharply [12]. Prolonged drought will reduce the amount of water in hydroelectric reservoirs, the amount of hydroelectricity reduced so it is necessary to increase the power from fossil energy sources (coal, oil, ...)[13], which will increase the emissions [14] load more than Calculation. The temperature in the city from $1960-2005$ increased by about $0.02^{\circ} \mathrm{C}$, in which from $1991-2005$ it increased by $0.033^{\circ} \mathrm{C}$ (the speed increased gradually)[15]. With climate change, it is expected that the temperature will increase even more. Studies of the Urban Heat Island (UHI) effect show that the air temperature in urban areas is significantly higher (up to $10^{\circ} \mathrm{C}$ ) than ambient temperatures in places [16]. Forest trees and rural areas. The reason for the difference in temperature is due to the dense concentration of infrastructure, buildings, urban houses, poor air convection, high energy consumption for transportation, industry and living, and the absence of green areas, surface water[17]. While UHI and extreme weather conditions (storms, storms and droughts) will promote greater energy consumption (due to the cooling needs of residents), the reduction in the performance and longevity of buildings, equipment and facilities will be improved. were, means, reducing labor productivity and entertainment activities of the people of the city, ... they also adversely affect the health of the elderly, children, the sick and the poor[18]. In fact, the heatwave5 in Europe in 2003 affected 20,000 people, mostly poor and lonely elderly. In Pradesh, India, heatwave has killed more than 1,000 people, mostly outdoor workers in urban settlements [15]. In addition, higher temperatures are expected to spread to hosts carrying human diseases such as dengue and malaria. Rising temperatures and changes in rainfall and drought can spread pests, pests and crop diseases, as well as adversely affecting ecosystems and growing seasons[9].

In addition, UHI will increase the harmful effects of air 
pollution on human health and property. Many urban areas will face more problems with air pollution because the concentration of air pollutants [19] can change correspondingly to climate change because their formation depends partly on temperature [20]. This is especially important in Asian and Latin American cities because most of these cities have the highest levels of air pollution. Greenhouse gas inventory (a form of emission source statistics) is one of the important factors in the response to climate change. Full greenhouse gas emissions database is considered an effective tool in developing climate change adaptation strategies and plans. Minimize $\mathrm{CO} 2$ emissions from vehicles on the basis of applying stricter emission standards (For example, raising the current standard of EURO 2 to EURO 4)[21]. Improve the transportation system with measures such as: Developing the public transport system[10], using standards for testing vehicle quality[22], fuel tax, having incentives for vehicles using renewable fuels[23]. Planning and building satellite cities, reducing the load of the current downtown areas; Investing in developing new energy technologies and using energy efficiently. Types of renewable energy have potential in the city. HCM is solar, biogas and wind energy[24]. Enhancing green areas to minimize the "urban heat island effect". Increasing public awareness (policy makers, businesses, people, especially those who are most affected by climate change). Propagate and educate about opportunities and benefits when implementing measures to prevent climate change and adaptive methods, improving coping capacity for community. Each city / country has its own strategy depending on the development context. Developed countries have built smart cities in the post-urbanization period. New York, Barcelona, London, Amsterdam, Munich, Tokyo ... need to be smarter to face the aging population, climate change, security and maintain a competitive position ... Each city has its own priority applying your competitiveness on strengths. Some countries have the resources and conditions to pilot new, iconic cities like Songdo - South Korea or Singapore. Emerging economies have large-scale investment potential such as China - 285 pilot projects in over 100 cities, India - building projects in 100 cities. Other countries that are also piloting new construction such as Malaysia have Putrajaya, and the United Arab Emirates is Dubai. However, it seems that new construction projects with the scale of being used as 'symbols' have a high investment cost and are suitable for a high-ability 'elite' population. The replication depends on the economic potential. Smart cities are a combination of technology and governance, including institutions. From a social perspective, the biggest benefit of developing a smart city is 'helping create a concerted action to face the challenge at a larger level'. This is the result of new management methods when promoting the application of new technologies. The goal of coordinated action is to better promote human capital, social capital and technological power to create a better, more sustainable life (Directorate General for Internal Policies, 2014, p. 18). Therefore, the most intelligent cities in Europe are respected for their success in addressing congestion and reducing $\mathrm{CO} 2$ emissions by organizing public bicycles, businesses and communities together saving energy and clean water, as well as participating, contributing initiatives to make the city safer and more friendly, not because of what technology they use. Cities with larger social capital or more mature institutions often lead in rankings for this reason.

TABLE I: ANNUAL AVERAGE TEMPERATURE CHANGE $\left({ }^{\circ} \mathrm{C}\right)$ IN VIETNAM, COMPARED TO 1980-1999, AVERAGE SCENARIO (B2)

\begin{tabular}{llllllllll}
\hline \hline $\begin{array}{l}\text { Climate } \\
\text { region }\end{array}$ & $\begin{array}{l}\mathbf{2 0 2} \\
\mathbf{0}\end{array}$ & $\begin{array}{l}\mathbf{2 0 3} \\
\mathbf{0}\end{array}$ & $\begin{array}{l}\mathbf{2 0 4} \\
\mathbf{0}\end{array}$ & $\begin{array}{l}\mathbf{2 0 5} \\
\mathbf{0}\end{array}$ & $\begin{array}{l}\mathbf{2 0 6} \\
\mathbf{0}\end{array}$ & $\begin{array}{l}\mathbf{2 0 7} \\
\mathbf{0}\end{array}$ & $\begin{array}{l}\mathbf{2 0 8} \\
\mathbf{0}\end{array}$ & $\begin{array}{l}\mathbf{2 0 9} \\
\mathbf{0}\end{array}$ & $\begin{array}{l}\mathbf{2 1 0} \\
\mathbf{0}\end{array}$ \\
\hline $\begin{array}{l}\text { Northw } \\
\text { est }\end{array}$ & 0.5 & 0.7 & 1.0 & 1.3 & 1.6 & 1.9 & 2.1 & 2.4 & 2.6 \\
$\begin{array}{l}\text { Northea } \\
\text { st }\end{array}$ & 0.5 & 0.7 & 1.0 & 1.2 & 1.6 & 1.8 & 2.1 & 2.3 & 2.5 \\
$\begin{array}{l}\text { Norther } \\
\text { n Delta }\end{array}$ & 0.5 & 0.7 & 0.9 & 1.2 & 1.5 & 1.8 & 2.0 & 2.2 & 2.4 \\
$\begin{array}{l}\text { North } \\
\text { Central }\end{array}$ & 0.5 & 0.8 & 1.1 & 1.5 & 1.8 & 2.1 & 2.4 & 2.6 & 2.8 \\
$\begin{array}{l}\text { South } \\
\text { Central }\end{array}$ & 0.4 & 0.5 & 0.7 & 0.9 & 1.2 & 1.4 & 1.6 & 1.8 & 1.9 \\
$\begin{array}{l}\text { Highlan } \\
\text { ds }\end{array}$ & 0.3 & 0.5 & 0.6 & 0.8 & 1.0 & 1.2 & 1.4 & 1.5 & 1.6 \\
$\begin{array}{l}\text { Souther } \\
\text { n }\end{array}$ & 0.4 & 0.6 & 0.8 & $\mathbf{1 . 0}$ & 1.3 & 1.6 & 1.8 & 1.9 & $\mathbf{2 . 0}$ \\
\hline \hline
\end{tabular}

In the period of 2012 - 2016, investment resources for environmental management activities in urban areas will continue to be strengthened and diversified. At the national and local level, many programs and projects related to environmental management have been implemented and expanded. However, the main funding source is still extracted from the state budget, in which, most of the projects and programs focus on building hygienic solid waste burial sites and treating waste. Institute, urban wastewater treatment. The proportion of urban areas with environmental treatment facilities has increased by about 4 $5 \%$ compared to the previous period, the implementation of the Master Plan on medical waste treatment in the 20112015 period also contributes to control and reduce the amount of medical waste to the environment. In addition, lending projects, grants from non-governmental organizations, international organizations with the participation of a number of businesses also have positive contributions to urban environmental protection. During this period, ODA funds for environmental projects reached about 3,769 million USD. In addition, the capital sources of socialization in solid waste collection and treatment activities and water pollution reduction are also increasing. The urban area is one of the key areas under the regular environmental monitoring program. Activities of environmental monitoring have been implemented for many years, thereby providing necessary information for environmental protection, serving communication and education, developing programs and projects to overcome environmental pollution. Along with that, the system of automatic environmental monitoring stations has also been strengthened installation and concentrated mainly in urban areas. Over the years of implementation, the environmental monitoring results have contributed to identifying and evaluating pollution sources and, at the same time, providing important data for the development of environmental reports for management. , disseminating information to the community. However, a major limitation to the current urban environmental monitoring system is that the number of continuous automatic environmental monitoring stations is too small, not enough to assess and 
publish environmental quality, leading to forecasting trends and changes in environmental quality are still limited. In addition, the issue of investment capital for monitoring activities at all levels is low, making monitoring of environmental quality changes inadequate and comprehensive.

\section{MANAGEMENT SOLUTION}

Climate change is no longer the 'dumb-ness' that scares people, but its manifestations and effects are more visible, more intense and more harmful. Awareness of it, accepting and adapting, and taking proactive measures to minimize harm and risk prevention is probably the most appropriate policy in the management of urban environment in our country and especially in the future. Even if climate change is not as expected, the proposed solutions will help to manage urban environment more sustainably, meet the needs of urbanization, population growth and socioeconomic development.

Ho Chi Minh City's ambition is to develop into a modern city by 2030 with a way of managing rapid and sustainable economic development. In order to realize sustainable development, it is necessary to integrate action plans to adapt to climate change. However, climate change adaptation should not be realized as a single goal. The results will be much more interesting if Ho Chi Minh City itself is committed to the goal of improving the quality of the already vibrant city. In each climate change adaptation project, and during the implementation of each proposed measure, both these goals can be combined. According to the Southern Hydrometeorology Station, from 2006 onwards, the tide level measured at Hoa An station in Nha Be district "is always higher than the previous year". Before 1999 , the highest tidal peak on the Saigon River was $1.36 \mathrm{~m}$, in 2007 it was $1.49 \mathrm{~m}$, by 2008 the tidal peak reached $1.54 \mathrm{~m}$ and by 2010 the tidal peak in Ho Chi Minh City had reached a record level 1, 58m[25][26][27]. Currently, Ho Chi Minh City has created many new flooding points in suburban districts. In addition to natural causes, many scientists believe that it may be because many canals or channels were encroached or deposited without water storage and the wetland has been leveled too much. And make the tidal peak in Ho Chi Minh City continuously increase in recent years. The recorded data is that the water level of rivers and canals in the city has increased by $1.5-2 \mathrm{~cm} /$ year while the sea level has only increased by $4-5 \mathrm{~mm} /$ year[28]. In addition, the urban drainage system is old, patchy and overloaded because it was built more than 50 years ago. While the new drainage projects are outdated in terms of input design data compared to the latest developments in the weather of Ho Chi Minh City and in these projects almost no mention of climate change impacts. Urban planning also needs attention. Currently Ho Chi Minh City's dike system is being upgraded, but to ensure that by 2050 flooding this area causes less damage that requires local authorities more efforts. For some areas particularly affected by climate change, in that case migration is the only solution[4]. According to climate change policy advisor of the United Nations Development Program in Viet Nam, Koos Neefjes, the expansion of the city to the lowlands must be stopped immediately and the population will be relocated and industrial plants out of town. Meanwhile, experts from the Netherlands (Rotterdam) proposed that the City develop towards the sea (Nha Be, Can Gio). Therefore, more research is needed on these proposals.

UNDP19 also proposed: "For example, embankment strengthening is needed to protect villages, communes, and cities including Ho Chi Minh City from typhoons. These phenomena will evolve in the direction of deterioration in the face of climate change. Storm waves can be mitigated by expanding and protecting mangrove forests along the coast, and even dykes need to be built and reinforced to ensure increased safety. Fences may be required to prevent flooding to protect large ports. Roads, bridges, and industrial areas need to be "shielded from the effects of climate", which means that designs must be adjusted to remain relevant when sea levels (average as well as peaks) rising, ensure drainage requirements, pay attention to water supply issues. The metro system in urban areas, the drainage and sewerage systems need to be adapted to the extreme cases of extreme rainfall and wastewater discharge. Public and private buildings must be solidified to avoid hazards from typhoons. This can be partly achieved by adjusting the standards and construction practices of buildings."

In order to ensure sufficient water supply in the dry season, prevention of saline water intrusion in the City, it is recommended to: Research modern technologies for brackish water treatment together with site study of water treatment plants and distribution networks. New water distribution. Research renewable technologies and encourage water reuse. ARUP (2010) proposed to build raw water reservoirs that help discharge saline water in the dry season (similar to Dau Tieng lake), can also be a source of quality raw water for the water supply system, providing flood control benefits and supplement groundwater sources if any to enhance Ho Chi Minh City's response to climate change[29].

Demand management, not only meets demand" to reduce future water consumption. The demand reduction needs to be implemented in 03 subjects: Irrigation, industry and daily life. Sustainable water resource management must include demand management (through price $\&$ fee tools, quantity norms, awareness education, information provision) and supply management (including searching for new water sources and reduce the rate of losses through the pipe network)[30].

\section{CONCLUSION}

As of December 2016, the whole country had 795 urban areas, with an urbanization rate of $35.2 \%$. The rapid urbanization speed has led to an overloaded urban infrastructure, causing adverse impacts on the environment. In recent years, urban environmental management has made significant progress, policies and legal regulations on urban environmental protection have been completed; investment and mobilization of resources for urban environmental protection have been strengthened; Many projects and programs to improve environmental quality and overcome pollution have been implemented; The quality of the air and water environment in some urban areas has improved 
markedly. However, besides the achieved results, there are still limitations and challenges in pollution planning and control, causing environmental pollution in many urban areas, especially urban areas. Great continues to happen. However, planning issues and implementation plans at the national and local levels are still facing many difficulties and challenges. In particular, the biggest challenge is the rapid increase of the number of urban areas, but the urban quality has not met the requirements; technical and social infrastructure systems are not synchronized, overloaded, leading to problems of traffic congestion, degraded urban water supply and drainage, causing local flooding and increasing environmental pollution. For urban groups that have a long history of development, the implementation of the master plan, according to functional sub-areas faces many difficulties due to the great population pressure, while the urban infrastructure has not met the requirements bridge development. In addition, the urban system is facing new challenges arising from the impacts of climate change and sea level rise, especially in coastal cities.

\section{REFERENCES}

[1] P. N. Duy, L. Chapman, and M. Tight, "Resilient transport systems to reduce urban vulnerability to floods in emerging-coastal cities: a case study of Ho Chi Minh City, Vietnam," Travel Behav. Soc., vol. 15 pp. 28-43, 2019.

[2] L. Hens et al., "Sea-level rise and resilience in Vietnam and the AsiaPacific: A synthesis," VIETNAM J. EARTH Sci., 2018.

[3] P. N. Duy, L. Chapman, M. Tight, L. V Thuong, and P. N. Linh, "Urban resilience to floods in coastal cities: Challenges and opportunities for Ho Chi Minh city and other emerging cities in southeast Asia," J. urban Plan. Dev., vol. 144, no. 1, p. 5017018 , 2017.

[4] I. A. Pervin, S. M. M. Rahman, M. Nepal, A. K. E. Haque, H. Karim, and G. Dhakal, "Adapting to urban flooding: a case of two cities in South Asia," Water Policy, 2019.

[5] A. T. Hoang, V. V. Le, V. V. Pham, and B. C. Tham, "An investigation of deposit formation in the injector, spray characteristics, and performance of a diesel engine fueled with preheated vegetable oil and diesel fuel," Energy Sources, Part A Recover. Util. Environ. Eff., pp. 1-13, 2019.

[6] A. Katzschner, F. Schwartze, B. Thanh, and M. Schmidt, "Introduction to Ho Chi Minh City," in Sustainable Ho Chi Minh City: Climate Policies for Emerging Mega Cities, Springer, 2016, pp. 5-17.

[7] R. Prizzia and J. Levy, "Towards climate security and sustainable security in the Asia-Pacific region," in Asia-Pacific security challenges, Springer, 2018, pp. 41-64.

[8] R. J. Nicholls, J. Hinkel, D. Lincke, and T. van der Pol, "Global Investment Costs for Coastal Defense through the 21st Century." The World Bank, 2019.

[9] D. Gilfillan, T. Nguyen, and H. Pham, "Coordination and health sector adaptation to climate change in the Vietnamese Mekong Delta," Ecol. Soc., vol. 22, no. 3, 2017.

[10] X. P. Nguyen, "The bus transportation issue and people satisfaction with public transport in Ho Chi Minh city," J. Mech. Eng. Res. Dev., 2019.

[11] C. J. van Leeuwen, N. P. Dan, and C. Dieperink, "The challenges of water governance in Ho Chi Minh City," Integr. Environ. Assess. Manag., 2016

[12] L. E. Erban, S. M. Gorelick, and H. A. Zebker, "Groundwater extraction, land subsidence, and sea-level rise in the Mekong Delta, Vietnam," Environ. Res. Lett., 2014.

[13] A. T. Hoang and V. V. Pham, "A study of emission characteristic, deposits, and lubrication oil degradation of a diesel engine running on preheated vegetable oil and diesel oil," Energy Sources, Part A Recover. Util. Environ. Eff., vol. 41, no. 5, pp. 611-625, 2019.

[14] A. T. Hoang and V. V. Pham, "Impact of jatropha oil on engine performance, emission characteristics, deposit formation, and lubricating oil degradation," Combust. Sci. Technol., vol. 191, no. 03 , pp. 504-519, 2019.

[15] C. Rosenzweig, W. D. Solecki, P. Romero-Lankao, S. Mehrotra, S. Dhakal, and S. A. Ibrahim, Climate change and cities: Second assessment report of the urban climate change research network. Cambridge University Press, 2018.

[16] M. M. Aboulnaga, A. F. Elwan, and M. R. Elsharouny, "Global Climate Change Adaptation Measures in Cities and Urban Areas," in Urban Climate Change Adaptation in Developing Countries, Springer, 2019, pp. 77-104.

[17] H. B. Dulal, "Cities in Asia: how are they adapting to climate change?," J. Environ. Stud. Sci., vol. 9, no. 1, pp. 13-24, 2019.

[18] S. Chatterjee, "Rights, risks and resilience: the 3Rs approach to childcentred climate change adaptation in Asian cities," in Responding to Climate Change in Asian Cities, Routledge, 2016, pp. 51-73.

[19] A. T. Hoang et al., "An absorption capacity investigation of new absorbent based on polyurethane foams and rice straw for oil spill cleanup," Pet. Sci. Technol., vol. 36, no. 5, pp. 361-370, 2018.

[20] A. T. Hoang, A. T. Le, and V. V. Pham, "A core correlation of spray characteristics, deposit formation, and combustion of a high-speed diesel engine fueled with Jatropha oil and diesel fuel," Fuel, vol. 244, pp. 159-175, 2019

[21] A. T. Hoang, Q. V. Tran, A. R. M. S. Al-Tawaha, V. V. Pham, and X. P. Nguyen, "Comparative analysis on performance and emission characteristics of an in-Vietnam popular 4-stroke motorcycle engine running on biogasoline and mineral gasoline," Renew. Energy Focus, vol. 28, pp. 47-55, 2019.

[22] V. V. Pham and D. T. Cao, "A brief review of technology solutions on fuel injection system of diesel engine to increase the power and reduce environmental pollution," J. Mech. Eng. Res. Dev., vol. 42, no. 1, pp. 01-09, 2019

[23] A. T. Hoang and V. V. Pham, "A review on fuels used for marine diesel engines," J. Mech. Eng. Res. Dev., vol. 41, no. 4, pp. 22-32, 2018.

[24] A. T. Hoang et al., "Power generation characteristics of a thermoelectric modules-based power generator assisted by fishboneshaped fins: Part II-Effects of cooling water parameters," Energy Sources, Part A Recover. Util. Environ. Eff., pp. 1-13, 2019.

[25] M. Nursey-Bray, R. Nicholls, J. Z. Vince, S. Day, and N. Harvey, Public participation, coastal management and climate change adaptation. Routledge, 2017.

[26] P. H. Hoang, A. T. Hoang, N. H. Chung, L. Q. Dien, X. P. Nguyen, and X. D. Pham, "The efficient lignocellulose-based sorbent for oil spill treatment from polyurethane and agricultural residue of Vietnam," Energy Sources, Part A Recover. Util. Environ. Eff., vol. 40, no. 3, pp. 312-319, 2018

[27] T. R. Zolnikov, "The World Adapting to Climate Change," in Global Adaptation and Resilience to Climate Change, Springer, 2019, pp. 117-132.

[28] A. T. Hoang, "Experimental study on spray and emission characteristics of a diesel engine fueled with preheated bio-oils and diesel fuel," Energy, 2019.

[29] K. Yasuhara, M. T. Nhuan, and N. N. Truc, "Adaptation to Climate Change-Induced Geodisasters in Coastal Zones of the Asia-Pacific Region," in Engineering Geology for Society and Territory-Volume 1, Springer, 2015, pp. 149-152.

[30] X. D. Pham, A. T. Hoang, D. N. Nguyen, and V. V Le, "Effect of Factors on the Hydrogen Composition in the Carburizing Process," Int. J. Appl. Eng. Res., vol. 12, no. 19, pp. 8238-8244, 2017. 